\title{
The Changing Economics of an Academic Structural Biology Core Facility Diana Tomchick ${ }^{1}$ \\ ${ }^{1}$ UT Southwestern Medical Center \\ diana.tomchick@utsouthwestern.edu
}

The mission of the UT Southwestern Medical Center's Structural Biology Laboratory (SBL) is to provide education and access to campus researchers in structural biology, with an emphasis on macromolecular single-crystal X-ray crystallography and single-particle Cryo-EM reconstruction. A critical role of the SBL is to provide mentoring and assistance to graduate and postdoctoral students through all stages of a structural project, from cloning to structure determination and model analysis. Since the establishment of the SBL in 2000, collaborations with more than 80 research groups on the UT Southwestern campus on over 150 projects, resulting in over 150 peer-reviewed publications and over $255 \mathrm{X}$-ray crystal structures deposited in the Protein Data Bank, as well as 5 Cryo-EM structures. Many of the most biologically interesting structural projects pursued through the SBL have also proven to be quite challenging ones, with difficulties ranging from protein production to structure validation and all the steps in-between. As a result, the majority of the SBL staff are Ph.D. level scientists with Research Faculty appointments and are involved in graduate level formal instruction. A detailed description of the funding mechanisms that established the SBL as well as the current support for a service lab that has responded to the growing structural biology needs of a major biomedical research university will be presented. A projection of future needs and services to be provided by the SBL will also be discussed, as well as the prospects for providing services to industrial customers. 